\title{
Gas chromatographic analysis of fatty acid composition in the freshwater fishes in North Sulawesi
}

\author{
Julius Pontoh*, Drayen Tumiwa \\ Chemistry Department, Faculty of Mathematics and Natural Sciences, Sam Ratulangi University, Jl. Kampus Unsrat, Kleak, Manado, Indonesia
}

*Corresponding author: pontohjulius@yahoo.com

\section{Article history}

Submitted 30 January 2018

Revised 23 March 2018

Accepted 31 March 2018

Published Online 30 April 2018

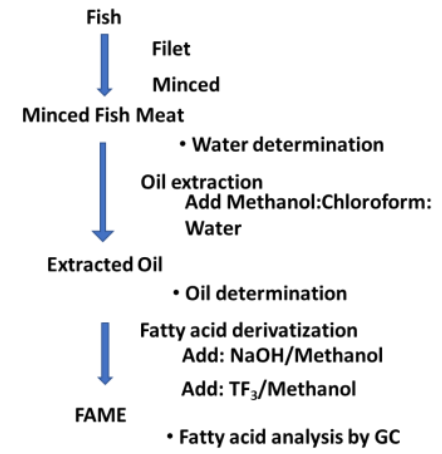

\begin{abstract}
Freshwater fishes are one of the nutritious food sources for many people, especially in Indonesia including in North Sulawesi. Other than its protein, the fish oils have an important source of specific energy as well as a nutraceutical in our lives. Some fatty acids, especially omega three fatty acids have been known for their functions in the prevention of some artery diseases. However, there is not so much information available about the composition of fatty acids in the freshwater fishes. Therefore, the purposes of this research are to determine the presence of fatty acids and their composition in the freshwater fishes. The fish samples, including tilapia (Major), carp (ikan Mas), catfish (lele) and snakehead (gabus) have been collected from various parts in North Sulawesi. Fatty acids were identified using standard fatty acid mix and then measured for their concentration using gas chromatography technique. It was found that the main fatty acids were successfully identified based on their abundances: concentration of oleic acid from $27.2 \%$ for snakehead to $42.2 \%$ for catfish, concentration of palmitic acid from $22.3 \%$ for carp to $26.9 \%$ for snakehead fish and concentration of linolenic acid from $11.9 \%$ for snakehead to $22.5 \%$ for carp. Among the freshwater fishes, the snakehead fish showed a unique fatty acid composition where docosahexaenoic acid (C22:6, DHA) was found in higher concentration.
\end{abstract}

Keywords: Fatty acid, freshwater fish, gas chromatography

(c) 2018 Penerbit UTM Press. All rights reserved

\section{INTRODUCTION}

Fish is generally used as one of the important sources of protein and lipid in human nutrition in Indonesia and particularly in North Sulawesi. The fish consumption in North Sulawesi ( $48 \mathrm{~kg} / \mathrm{cap} / \mathrm{year}$ ) is one among the five highest consumptions in Indonesia with the average of $39 \mathrm{~kg} / \mathrm{cap} /$ year (Indonesian Ministry of Marine and Fishery, 2017). Although the seawater fish is the main important resources for the people in this area, freshwater fishes consisting of protein and lipid sources with their availabilities in one year without any particular break have not been studied so far. Moreover, the sea water fish supply is sometimes lower during certain weather conditions (such as at moonlight days or heavy windy seasons) while the freshwater fish supply does not depend on the weather conditions.

The role of lipids in human nutrition is not only as the source of energy, but lipids are also very important to maintain the human body. The information on fatty acid composition is highly required due to their important functions in human health. For example, polyunsaturated omega three fatty acids such as EPA (eicosapentaenoic acid) and DHA (docosahexaenoic acid) have a prevalent impact to prevent atherosclerosis diseases and can improve the human brain activity and eye visuality (Kaur et al., 2014). Recent studies showed that EPA alone can reduce triacylglycerol and lowdensity lipoprotein cholesterol as well as prevent the artery inflammation (Singh et al., 2014).

The fatty acid composition of the fish oil is varying from their species, food supplies and the other environments conditions such as water temperature and $\mathrm{pH}$ (Fallahab et al., 2013). Therefore, the composition of fatty acid will be varied from time to time and from one place to the other place. The fatty acid from various organism products is generally analyzed using gas chromatography method. Various reports for fatty acids in seawater and freshwater fishes have been reported such as sea water fishes (Ozogul et al., 2009; Pratama et al., 2011), fresh water fishes (Ngadiarti et al., 2013) and both sea water and fresh water fishes (Mohanty et al., 2016; Sorin et al., 2013; Toyomizu and Tomiyasu, 1962; Vlieg and Body, 1988). Until now, the information on the fatty acid composition of freshwater fish in North Sulawesi has been very limited. There are several publications about freshwater fish, including catfish and carp (Ngadiarti et al., 2013; Mohanty et al., 2016; Sorin et al., 2013; Toyomizu and Tomiyasu, 1962; Vlieg and Body 1988). One of the publication is related to it processing for fermentation process (Ngadiarti et al., 2013). Therefore, it is important to perform some research about the fatty acid composition in various fishes popularly marketed in North Sulawesi.

\section{EXPERIMENTAL}

Sample fishes were collected from various parts or areas in the province of North Sulawesi. The fish samples have 4 types; tilapia (mujair, Oreochromis mossambicus), carp (ikan mas, Cyprinus carpio), catfish (lele, Clarias gariepinus) and snakehead (gabus, Channa striata). Three fishes were then collected for each species fresh after cached from the ponds. Samples were stored in an ice bucket for transportation to the laboratory prior to the analysis. Fish samples were cleaned from the skin and bones, and the meat was 
minced. About $30 \mathrm{~g}$ of minced meat was weighed and the oils were determined and followed by modification using a Bligh and Dryer method (Bligh and Dryer, 1959). A $30 \mathrm{~g}$ of minced meat sample was blended with a mixture of $60 \mathrm{~mL}$ methanol and $30 \mathrm{~mL}$ chloroform. After blending for 2 minutes, a $30 \mathrm{~mL}$ of water was added and blended for another 30 seconds. After that, a $30 \mathrm{~mL}$ of water was added again and then blended for another 30 seconds. Samples were filtrated and the desired samples were dried in a rotary evaporator at $40{ }^{\circ} \mathrm{C}$. Dried samples were placed in the aluminum foil and then wrapped the bottles for sample preparation in the freezer until the analysis procedure. Lipid content was determined based on the weight of dried extracted lipid by the weight of the fresh sample. Water content analysis was prepared using a $3 \mathrm{~g}$ of fresh meat dried in the oven at $105^{\circ} \mathrm{C}$ for 24 hours. Water content was then calculated based on the dried samples to the fresh samples.

\section{Sample derivation}

Sample preparation for analysis using gas chromatography was performed according to the following method in our laboratory procedure. Typically, a $50 \mathrm{mg}$ of extracted oils was measured in a 5 $\mathrm{mL}$ of sample bottle and added to $1.5 \mathrm{~mL}$ of $0.5 \mathrm{M}$ sodium hydroxide $(\mathrm{NaOH})$ in methanol. The mixture was heated to $100{ }^{\circ} \mathrm{C}$ for 5 minutes. After performing the cooling, boron trifluoride $\left(\mathrm{BF}_{3}\right)$ in $12 \%(2 \mathrm{~mL})$ in methanol was added and followed by heating in $100{ }^{\circ} \mathrm{C}$ for 30 minutes. After cooling procedure, $1 \mathrm{~mL}$ of hexane was added and settled. A $5 \mathrm{~mL}$ saturated sodium chloride $(\mathrm{NaCl})$ solution was also poured into the mixture for the separation purpose. The top layer consisting of fatty acid methyl ester (FAME) was collected for GC sample analysis. Figure 1 shows the process from the sample preparation of fishes until oil extraction and determination for fatty acid derivatization and gas chromatography analysis.
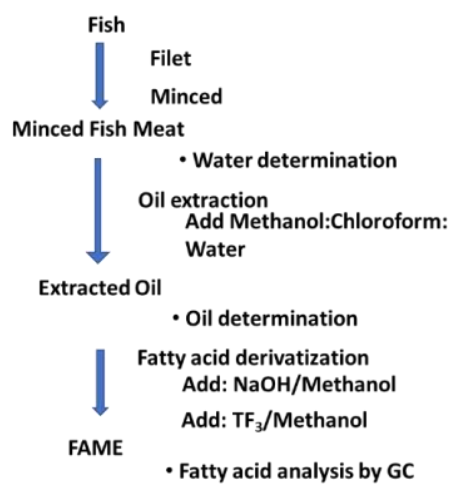

Fig. 1 Flow chart of sample preparation and analysis.

\section{Gas chromatography analysis}

The fatty acid methyl ester was analyzed using Shimadzu GC2014 with a flame ionization detector. This GC was equipped using RTX wax column with $30 \mathrm{~m}$ in length, $0.25 \mathrm{~mm}$ in diameter and a $0.25 \mu \mathrm{m}$ film. The injection was performed in a split mode $1: 10$ and the injection port temperature was set at $240{ }^{\circ} \mathrm{C}$. The oven temperature was programmed at $120^{\circ} \mathrm{C}$ for 7 minutes and then increased up to 240 ${ }^{\circ} \mathrm{C}$ with $10{ }^{\circ} \mathrm{C} /$ minute increment. The temperature was kept at $240{ }^{\circ} \mathrm{C}$ for 15 minutes. The detector was used at a temperature of $300{ }^{\circ} \mathrm{C}$ The Helium gas was set at a flow of $3 \mathrm{~mL} /$ minute with a pressure of $100 \mathrm{kPa}$. A $1 \mu \mathrm{L}$ of the sample was injected into gas chromatography injection port for every sample.

\section{Fatty acid determination}

In order to determine the composition of fatty acids in the sample, a FAME analytical reference material as a mixture of $\mathrm{C} 8-\mathrm{C} 24$ (Supelco) was measured along with a coconut oil sample derivatized following the above method. Coconut fatty acid was used to verify the main fatty acids (Pontoh, 2016). The reason for using two standard fatty acids was due to the FAME mix C8-C24 (Supelco) has been generated previously (Tanaty et al., 2016) and the present study of the fatty acid retention time had changed quite significantly. The individual fatty acid concentration was determined based on the external FAME mix standard (Tanaty et al., 2016). In this case, fatty acid content in $\mathrm{mg} / \mathrm{mL}$ was calculated as the peak area of the sample fatty acid divided by the related standard fatty acid times the concentration of standard fatty acid as supplier declared. The fatty acid concentration is expressed in average in both $\mathrm{mg} / \mathrm{ml}$ and percentage of the content from three replicates.

\section{RESULTS AND DISCUSSION}

\section{Chromatography analysis}

The standard chromatogram of fatty acid methyl ester can be seen in both Figs. 2 and 3. Figure 2 shows the fatty acid methyl esters from FAME mix C8-C24. In this figure, 14 peaks can be identified as fatty acid methyl esters; C-8:0, C-10:0, C-12:0, C-14:0, C-16:0, C-16:1, C18:0, C-18:1, C-18:2, C-18:3, C-20:0, C-22:0, C-22:1 and C-24:0. These peaks can be assigned for methyl caprylate, methyl caprate, methyl laurate, methyl myristate, methyl palmitate, methyl palmitoleate, methyl stearate, methyl oleate, methyl linoleate, methyl linoleate, methyl arachidate, methyl behenate, methyl erucate and methyl lignocerate, respectively (Table 1).

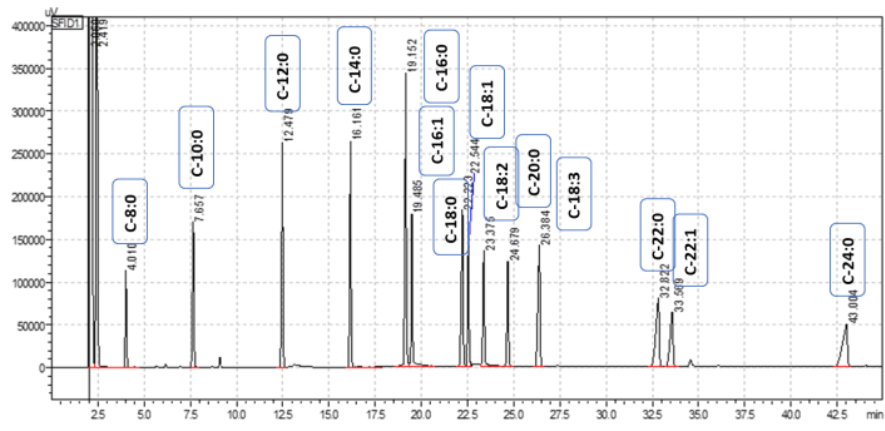

Fig. 2 Chromatogram of FAME mix C8-C24 standard.

Table 1 Retention time, molecular formula and the trivial name of standard and coconut fatty acids.

\begin{tabular}{ccccl}
\hline \multirow{2}{*}{ Peak } & \multicolumn{2}{c}{ Retention Time } & $\begin{array}{c}\text { Short- } \\
\text { hand }\end{array}$ & \multicolumn{1}{c}{ Trivial Name } \\
\cline { 2 - 4 } & $\begin{array}{c}\text { FAME mix } \\
\text { C8-C24 }\end{array}$ & $\begin{array}{c}\text { Coconut } \\
\text { Oil }\end{array}$ & $\begin{array}{c}\text { Clature } \\
\text { lann }\end{array}$ & \\
\hline 1. & 4.010 & 4.193 & C-8:0 & Methyl Caprylate \\
2. & 7.657 & 7.991 & C-10:0 & Methyl Caprate \\
3. & 12.479 & 12.130 & C-12:0 & Methyl Laurate \\
4. & 16.161 & 15.072 & C-14:0 & Methyl Myristate \\
5. & 19.152 & 17.482 & C-16:0 & Methyl Palmitate \\
6. & 19.485 & & C-16:1 & Methyl Palmitoleate \\
7. & 22.223 & 19.617 & C-18:0 & Methyl Stearate \\
8. & 22.544 & 19.856 & C-18:1 & Methyl Oleate \\
9. & 23.375 & 20.366 & C-18:2 & Methyl Linoleate \\
10. & 24.679 & & C-20:0 & Methyl Arachidate \\
11. & 26.384 & 23.991 & C-18:3 & Methyl Linoleate \\
12. & 32.822 & & C-22:0 & Methyl Behenate \\
13. & 33.569 & & C-22:1 & Methyl Erucate \\
14. & 43.004 & & C-24:0 & Methyl Lignocerate \\
\hline
\end{tabular}

Figure 3 shows a standard fatty acid methyl ester from coconut oil for further identification of the main fatty acids in fish oil. There is a slight reduction of the retention time of the FAME standard solution from the coconut and fish oil chromatogram due to the column degradation. There are significant differences in fatty acid retention times between the two chromatograms (Table 1). This is due to the 
generated times between the two standards are quite different. The FAME mix C8-C24 was run previously (Tanaty et al., 2016), but the coconut oil fatty acids were run at the present time along with the sample fish oil fatty acids. It can be seen in Table 1 and Fig. 3 that the retention times of higher fatty acids (C-14:0 and higher) in coconut oil are decreased compared to that of the FAME mix C-4:0 - C-24:0). For the peak $\mathrm{C}-18: 3$, the different retention time was about 2 and half minutes. This result was due to the deterioration of the column over time (over a year).

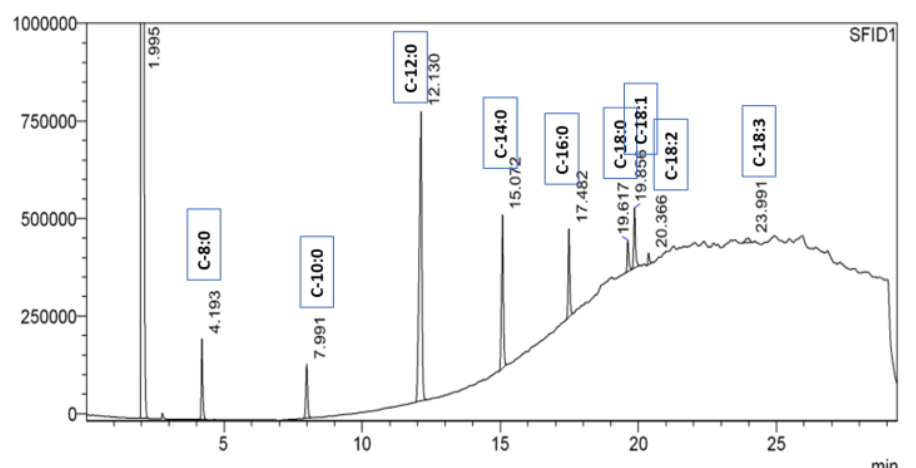

Fig. 3 Chromatogram of fatty acid methyl ester from coconut oil.

The chromatograms of fish oil can be seen in Figs. 4 to 7 . The sequences of individual fatty acid were correlated to the standard FAME mix (Fig. 2) and the main fatty acids in fish oil were identified base on the retention time of fatty acids in coconut oil (Fig. 3). The chromatogram of fatty acid methyl esters from tilapia (Fig. 4) shows the main fatty acids are oleic acid followed by palmitic and linoleic acid. On the other hand, the chromatogram of snakehead (Fig. 7) shows the reduction of oleic acid but increased for palmitic, linoleic and docosahexaenoic acid and eicosapentaenoic acid.

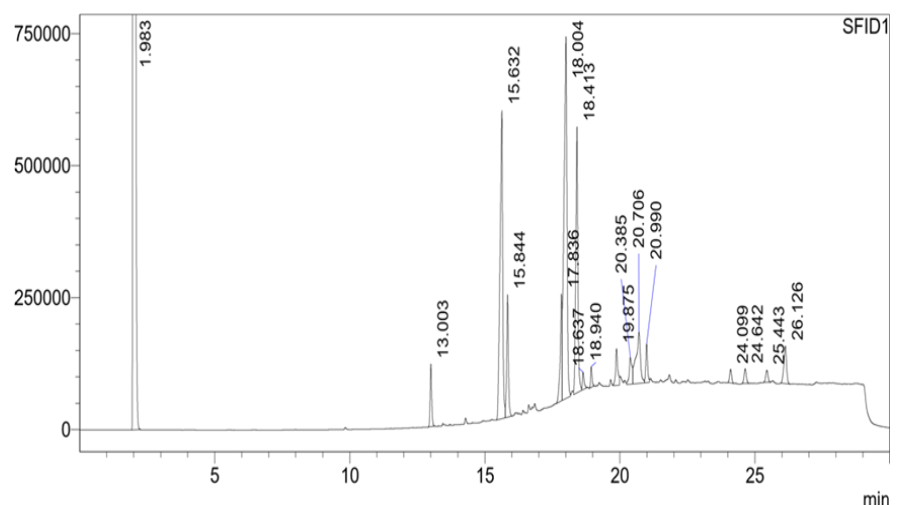

Fig. 4 Chromatogram of fatty acid methyl ester from tilapia.

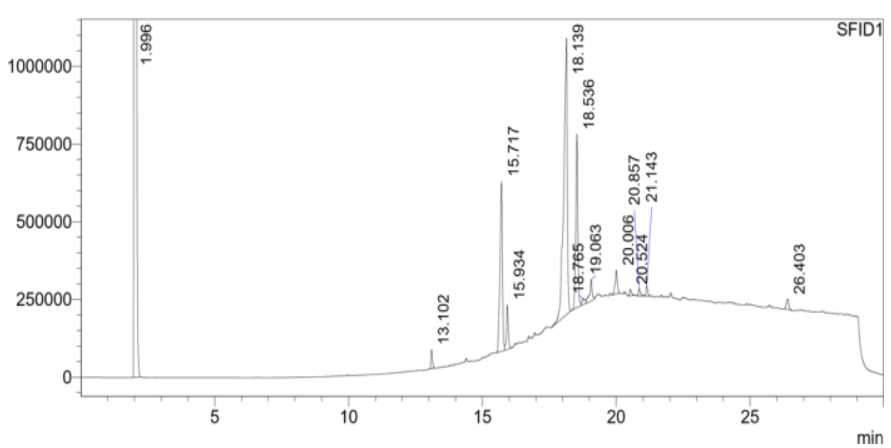

Fig. 5 Chromatogram of fatty acid methyl ester from carp.

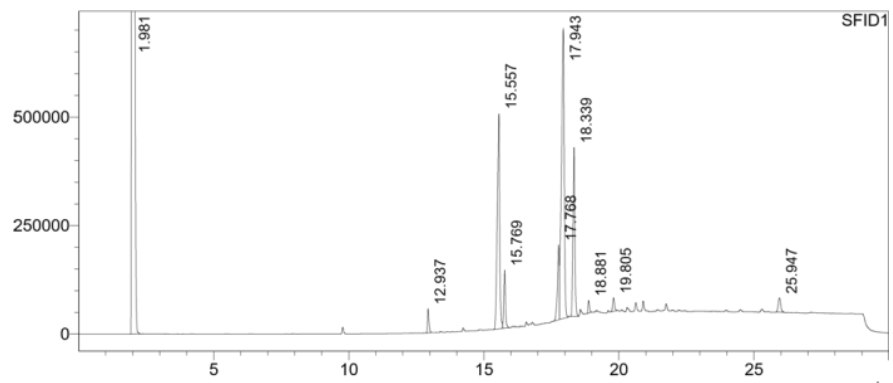

Fig. 6 Chromatogram of fatty acid methyl ester from catfish.

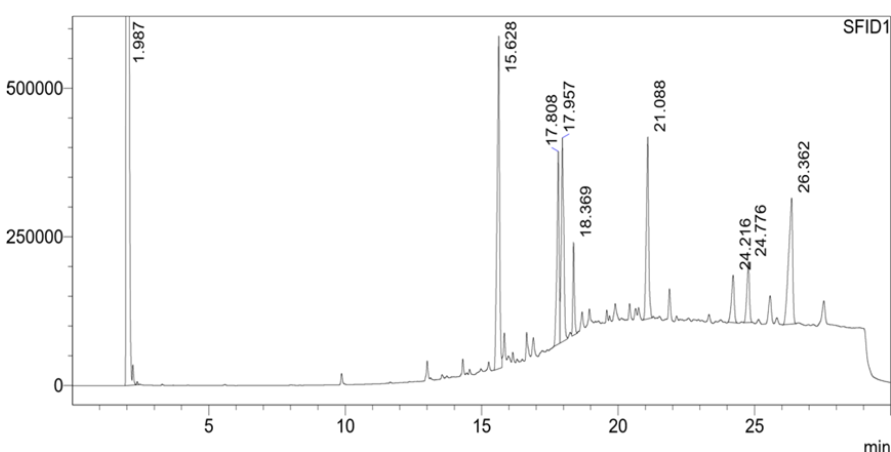

Fig. 7 Chromatogram of fatty acid methyl ester from catfish.

\section{Water content}

The water content of the sample can be seen from Table 2. The water content varies from 69.2 to $84.4 \%$. These results are similar to the carp and catfish water content from India (Mohanty et al., 2016), carp contains more water than catfish (77 and $75 \%$, respectively). Catfish has the lowest water content and followed by carp and tilapia. The highest water content is observed on the snakehead.

\section{Lipid content}

Lipid content of the samples can be seen from Table 2. The lipid content varies from 0.1 to $3.0 \%$. Snakehead contains the lowest oil followed by tilapia. Catfish contains the highest oil followed by carp. Therefore, the catfish belongs to low lipid meat containing 2-4\% oil concentration (Mohanty et al., 2016), while tilapia, carp, catfish, and snakehead belong to the lean meat fish (Mohanty et al., 2016). The snakehead belongs to the fish with very low oil content. Chasanah et al. (2015) reported that snakehead oil content depended on the growing environment of the fish. At wild environment, the oil content was $0.4 \%$ and in the cultured environment was $2.7 \%$. As shown in Table 2, the oil content of fish is related to the water content. The higher the oil content, the lower the water content.

Table 2 Percentage of water and oil contents in selected freshwate fish.

\begin{tabular}{ccc}
\hline Fish species & Water Content & Oil Content \\
\hline Tilapia & $79.9 \pm 4.3$ & $0.34 \pm 0.0$ \\
Carp & $75.8 \pm 4.8$ & $1.55 \pm 0.1$ \\
Catfish & $69.2 \pm 3.3$ & $2.95 \pm 0.2$ \\
Snakehead & $84.4 \pm 4.1$ & $0.12 \pm 0.0$ \\
\hline
\end{tabular}

\section{Fatty acid composition}

The fatty acid composition of the selected freshwater fishes can be seen in Table 3. The oleic acid is the highest fatty acids in tilapia, carp, and catfish. The snakehead contains moderate oleic acid. Palmitic acid is the second abundantly fatty acid in all sample freshwater fishes. The main fatty acid composition (oleic and palmitic acid) of carp oil is very close to the previous report in New Zealand 
(Vlieg and Body, 1988; $26 \%$ of oleic and $17 \%$ of palmitic in carp) and from Japan (Toyomizu and Tomiyasu, 1962; 28\% of oleic and 17\% of palmitic in carp), but slightly different from India (Mohanty et al., 2016) where the palmitic acid is the main fatty acid (35\%) and oleic acid $(17 \%)$.

Tilapia contained high oleic acid (39.7\%) and palmitic acid $(22.3 \%)$ but low in EPA (3\%) and no EPA. These numbers are different from that reported ones by Ramli et al. (2015) that Tilapia contained very high in Palmitoleic acid (49.9\%). These phenomena could be due to the difference in the source of fish. The main fatty acids in catfish are oleic acid and then followed by palmitic and linoleic acids. These findings are similar to the catfish fatty acids as reported from Bogor, West Java (Ngadiarti et al., 2013), except the second abundantly fatty acid was oleic acid. The fatty acids from catfish from Japan (Toyomizu and Tomiyasu, 1962) were reported having high in oleic and palmitic acids, but it was also significantly high in DHA.

Catfish consisted of the highest oleic acid $(42.2 \%)$ while the snakehead only contains $27.2 \%$ and the same amount of palmitic acid (26.9\%). Snakehead contained a significant amount of EPA $(7.3 \%)$ and DHA (11.0\%). The fatty acid composition in snakehead has been reported contradictory. The highest number of palmitic acid content reported by Zurimi et al. (2006) and Muhamad and Mohamad (2012), which was 30 and $22 \%$, respectively, while Ramli et al. (2016) reported only $6 \%$. On the other hand, Ramli et al. (2016) claimed that the palmitoleic acid in snakehead was high (26\%). These data could be due to the differences in the fish samples that collected from different environments, but also could be due to the differences in analytical methods. Since Muhamad and Mohamad (2012) and Ramli et al. (2015) used a GC-mass spectrometer, it is expected that the fatty acids identification should be very accurate.

The fatty acid composition of snakehead in this experiment is quite different from the other fishes. Even though the oleic acid is still the highest percentage of fatty acids, it provides almost the same level to that of the palmitic acid. The almost equal number of linoleic, DHA and stearic acids are very different from the other fishes with fatty acid composition. These fatty acid contents are similar to those reported by Ramli et al. (2015). This fish has significantly high content of EPA, which is very important for coronary disease prevention (Singh et al., 2016).

Table 3 Fatty acid composition in selected freshwater fish.

\begin{tabular}{|c|c|c|c|c|c|c|c|c|}
\hline \multirow{2}{*}{ Fatty acids } & \multicolumn{2}{|c|}{ Tilapia } & \multicolumn{2}{|c|}{ Carp } & \multicolumn{2}{|c|}{ Catfish } & \multicolumn{2}{|c|}{ Snakehead } \\
\hline & $\mathrm{mg} / \mathrm{mL}$ & $\%$ & $\mathrm{mg} / \mathrm{mL}$ & $\%$ & $\mathrm{mg} / \mathrm{mL}$ & $\%$ & $\mathrm{mg} / \mathrm{mL}$ & $\%$ \\
\hline Lauric acid & $1.6 \pm 0.1$ & 3.6 & $0.9 \pm 0.1$ & 1.9 & $1.3 \pm 0.1$ & 2.4 & $0.5 \pm 0.0$ & 1.0 \\
\hline Palmitic acid & $10.0 \pm 0.8$ & 22.4 & $11.3 \pm 0.7$ & 22.3 & $14.8 \pm 0.9$ & 25.7 & $13.8 \pm 0.9$ & 26.9 \\
\hline Palmitoleic acid & $6.0 \pm 0.4$ & 13.6 & $4.7 \pm 0.3$ & 9.2 & $5.9 \pm 0.5$ & 10.1 & $2.5 \pm 0.2$ & 4.8 \\
\hline Stearic acid & $1.8 \pm 0.1$ & 4.3 & $1.0 \pm 0.0$ & 3.6 & $2.1 \pm 0.2$ & 3.3 & $5.2 \pm 0.3$ & 10.0 \\
\hline Oleic acid & $16.0 \pm 1.0$ & 35.6 & $18.87 \pm 1.0$ & 39.7 & $24.8 \pm 3.9$ & 42.2 & $14.0 \pm 0.8$ & 27.2 \\
\hline Linoleic acid & $8.2 \pm 0.5$ & 18.6 & $11.4 \pm 0.7$ & 22.5 & $8.9 \pm 0.5$ & 15.1 & $6.0 \pm 0.4$ & 11.9 \\
\hline Linolenic acid & $0.6 \pm 0.0$ & 1.3 & $0.9 \pm 0.1$ & 1.6 & $0.5 \pm 0.0$ & 0.7 & & \\
\hline Eicosapentaenoic acid & & & $0.7 \pm 0.1$ & 1.2 & & & $3.7 \pm 0.2$ & 7.3 \\
\hline Docosatetraenoic acid & & & & & & & $2.9 \pm 0.2$ & 5.8 \\
\hline Docosahexaenoic acid & $2.4 \pm 0.1$ & 3.0 & $0.7 \pm 0.0$ & 0.9 & $0.6 \pm 0.0$ & 0.6 & $5.7 \pm 0.3$ & 11.0 \\
\hline Total & 44.8 & 100 & 49.3 & 100 & 58.6 & 100 & 51.3 & 100 \\
\hline
\end{tabular}

\section{CONCLUSION}

The main fatty acids in selected fish from North Sulawesi are oleic acid with the concentration of $27.2 \%$ for snakehead to $42.2 \%$ for catfish, palmitic acid with concentration from $22.3 \%$ for carp to $26.9 \%$ for snakehead fish and linolenic acid with concentration from $11.9 \%$ for snakehead to $22.5 \%$ for carp. Among the freshwater fishes, the snakehead fish has a unique fatty acid composition, it has a high concentration of docosahexaenoic acid (C22:6, DHA).

\section{REFERENCES}

Bligh, E. G., Dryer, W. J. 1959. A rapid method of total lipid extraction and purification. Can. J. Biochem. Physiol. 37, 911-917.

Chasanah, E., M. Nurilmala, A. R. Purnamasari, Fithriani, D. 2015. Chemica composition, albumin content and bioactivity of extract protein of native and cultured snakehead. (in Indonesian). JPB Kelautan dan Perikanan 10(2), 123132.

Fallahab, A. A., Nematollahi, A., Saei-Dehkordiab, S. 2013. Proximate composition and fatty acid profile of edible tissues of Capoeta damascina (Valenciennes, 1842) reared in freshwater and brackish water. J. Food Comp. Anal. 32, 150-154.

Indonesian Ministry of Marine and Fishery. 2017. Fish Consumption Number 2010-2015 (Angka Konsumsi Ikan 2010-2015), http://statistik.kkp.go.id/sidatik-dev/index.php?m=3\&id=2.
Kaur, N., Chugh, V., Gupta, A. K. 2014. Essential fatty acids as functional components of foods - A review. J. Food Sci. Technol. 51(10), 2289 2303

Mohanty, B. P. Ganguly, S., Mahanty, A., Sankar, T. V., Anandan, R., Chakraborty, K., Paul, B. N., Sarma, D., Dayal. J. S., Venkateshwarlu, G., Mathew, S., Asha, K. K., Karunakaran, D., Mitra, T., Chanda, S., Shahi, N., Das, P., Akhtar, M. S., Vijayagopal, P., Sridhar, N. 2016. DHA and EPA content and fatty acid profile of 39 food fishes from India. BioMed Res. Inter. 2016, Article ID 4027437.

Muhamad, N. A., Mohamad, J. 2012. Fatty acid composition of selected Malaysian fishes. Sains Malaysiana 41(1), 81-94.

Ngadiarti, I. C., Kusharto, M., Briawan, D., Marliyati, S. A., Sayuthi, D. 2013. Fatty acid contents and physico-chemical characterization of catfish oil and fermented catfish oil. Penelitian Gizi dan Makanan 36(1), 82-90.

Ozogul, Y. A., Ozogul, F. O, Cicek, E., Polat, A., Kuley, E. 2009. Fat content and fatty acid compositions of 34 marine water fish species from the Mediterranean Sea. Int. J. Food Sci. Nut. 60(6), 464-475.

Pontoh, J. 2016. Gas chromatographic analysis of medium chain fatty acids in coconut oil. J. Pure App. Chem. Res. 5(3), 157-161.

Pratama, R. I., Awaluddin, M. Y., Ishmayana, S. 2011. Composition of fatty acids in tongkol, layur and tenggiri from Pameungpeuk, Garut. Jurnal Akuatika 2 (2).

Ramli, S. S., Zaidul, L. S., Abdul Manap, M. Y., Mohamed, S. N. 2015. Comparison studies of fatty acids profiles extracted from selected Malaysian seawater and freshwater fish wastes. Proceedings of the IRES 23rd International Conference, Dubai, UEA $29^{\text {th }}$ December 2015, 13-18. 
Singh, S., Arora, R. R., Singh, M., Khosia, S. 2016. Eicosapentaenoic acid versus docosahexaenoic acid as option for vascular risk prevention: A fish history. Am. J. Therapeutic. 23(3), 905-910.

Sorin R. Bratu, A., Mihalache, M., Hanganu, A., Chira, N. A., Todasca, M. C., 2013. Quantitative determination of fatty acids from fish oil using GC-MS method and 1H-NMR spectroscopy. U.P.B. Sci. Bull., Series B. 75 (2).

Tanaty, M., Pontoh, J., Fatimah, F. 2016. Optimization of GC Shimadzu-2014 for fatty acid methyl ester (FAME) analysis. (In Indonesian). Jurnal MIPA Unstrat Online 5(1), 6-9.
Toyomizu, M, Tomiyasu, Y. 1962. Analysis of fatty acid composition of fish oil by gas-liquid chromatography. Bul. Jap. Soc. Sci. Fisheries. 28 (5), 526-533

Vlieg, P., Body, D. R. 1988. Lipid contents and fatty acid composition of some New Zealand freshwater finfish and marine finfish, shellfish, and roes. N. Z. F. Marine Freshwater Res. 22, 151-162. 